\title{
Determinants of Policy Response: The Case of the Partnership Long-Term Care Insurance Program
}

\author{
Haizhen Lin and Jeffrey Prince ${ }^{1}$
}

July, 2014

\begin{abstract}
$\underline{\text { Abstract }}$
Building on the findings of Lin and Prince (2013), we analyze several additional potential determinants of response to the partnership long-term care (PLTC) program, in addition to wealth. The determinants we consider are bequest motives, financial literacy, and program awareness. We find mild evidence that intent to bequest influences individual purchases of the partnership program. However, we find strong evidence that program awareness is necessary for response while financial literacy notably increases responsiveness. We also find that, even with these additional controls, a difference in response across wealth levels persists, suggesting that Medicaid crowd-out is still important in determining uptake of this program. These findings suggest that increasing response to the program among the middle class (the stated target group) requires increased education about the program's benefits and increased efforts to create awareness of the program existence, at least among the middle class.
\end{abstract}

Keywords: private long-term care insurance, partnership long-term care program, policy response JEL: I13, I18, I38

\footnotetext{
${ }^{1}$ Both authors are in the Department of Business Economics and Public Policy in the Kelley School of Business at Indiana University. They can be reached at hzlin@indiana.edu and jeffprin@indiana.edu, respectively.
} 


\section{Introduction}

Only about 10\% of Americans have any kind of insurance to cover their long-term care (LTC) needs. The majority of them rely on Medicaid, which has caused several complications. First, it exacerbates the financial burden of the government, especially given the increasing demand for LTC due to the aging of the baby boomer generation. Second, it provides disincentives to increase quality of LTC primarily because of predetermined Medicaid reimbursement rates. Third, it results in welfare losses due to under-insurance.

Increasing private LTC insurance coverage has thus been the crux of addressing the above issues. The Partnership Long-term Care Insurance Program (PLTC or partnership program) is one recent policy intervention. This program is a partnership between state Medicaid programs and private insurers. It offers individuals who purchase LTC insurance greater Medicaid asset protection. While the partnership program was only available for four states at its inception, the passage of the Deficit Reduction Act in 2005 provides permission to all states to adopt this program.

The partnership program has generated enthusiasm and optimism among policy makers and practitioners. By 2010, thirty-three more states (beyond the initial four pilot states) had adopted. However, the existing evidence has found that adoption of the partnership program has, at best, a modest impact on LTC insurance purchasing. Perhaps more interesting, individuals with high asset levels (80th percentile) respond significantly to the program (increasing their likelihood of purchase by 15\%), but individuals below the 80th percentile show virtually no response (Lin and Prince, 2013). This is in spite of the fact that the program was explicitly aimed at middle-income individuals, considered most likely to be on the margin for Medicaid if confronted with long-term care expenses.

The finding that only the wealthy respond to the program is surprising, especially given that they are not the target of the program. We aim to investigate what is driving such differential responses along wealth levels. Medicaid crowd-out is a likely cause (Brown and Finkelstein, 2008). However, the implicit 
tax at high wealth levels is the lowest, and the program is expected to have the least effect on reducing such a tax for the rich. In this study, we draw from the existing literature on LTC insurance three plausible drivers of individuals’ response to the PLTC program: intent to bequest, financial literacy, and program awareness. While there are many variables that might predict LTC insurance purchase overall, these three are particularly relevant toward explaining differential responses in LTC insurance purchase behavior to introduction of the partnership program. Specifically, since the partnership program can increase permanently sheltered assets, individuals’ response to this feature may differ depending on their intent to ultimately bequest assets; and, as the availability and features of the partnership program are not universally known and understood, it is natural to expect that variation in financial literacy and awareness levels can explain differences in response.

Beyond any direct effect these variables may have on response rates to the program, to the extent that these variables are correlated with wealth, they may help explain differential responses according to wealth, in addition to Medicaid crowd-out. Our data allow us to capture variation along these three dimensions via variables such as a measure of the importance of leaving a bequest (intent to bequest), work experience (financial literacy) and Internet activity (awareness of the program). ${ }^{2}$ Depending on what is driving this response, our study could shed light on how to design policy instruments to achieve the ultimate goals of the partnership program.

We find that bequest motives are somewhat predictive of response to the program. In particular, we find that the wealthy respond to the program less when there is a strong bequest motive; however, this effect, while notable in size, is not statistically significant. This finding is consistent with the idea that those who have greater bequest motives tend to self insure more (Lockwood, 2011), and thus may be relatively less responsive to a policy change designed to increase the benefits from purchasing LTC insurance. In contrast, our results concerning financial literacy and program awareness are quite strong.

\footnotetext{
2 This is because a lot of information regarding the PLTC program is offered online. See Section 3 for more discussions.
} 
Specifically, we only see response to the program among those who actively use the Internet, and the response is notably stronger among those who have worked in the financial sector. Regarding the latter finding, we see response to the program by both middle- and high-asset individuals with financial literacy, although the effect is still stronger for those with high assets.

These findings suggest that being active on the web is predictive of individuals being aware of the program's existence (which is necessary for them to respond), and working in the financial sector is predictive of understanding the program's benefits, which results in higher response rates. Lastly, while awareness, financial literacy, and possibly bequest intent, appear to be important determinants of differential response rates to the program, heterogeneous responses along wealth levels still persist. Thus, it appears that Medicaid crowd-out is the primary driver of the differences we find along wealth levels, and these other measures serve as additional factors that determine how individuals will respond to the program.

Our findings have two policy implications. First, given the importance of financial literacy, it is crucial for the government to educate consumers to achieve the success of any policy intervention. Second and more importantly, efforts to increase awareness among the middle class may be fruitful toward the aim of increasing uptake of LTC insurance.

\section{The PLTC Program and Previous Findings}

\subsection{The PLTC Program}

The partnership for long-term care (PLTC) program was initiated and developed by the Robert Wood Johnson Foundation in the 1980s. Unlike other policy instruments that work to reduce the costs associated with purchasing LTC insurance (e.g., tax subsidies), the PLTC program aims to increase 
insurance take-up by offering an added benefit of long-term care insurance through easier access to Medicaid coverage.

It is common knowledge that Medicaid covers LTC for individuals that pass various eligibility tests, such as income and medical needs. There is concern that because of Medicaid's role as the last resort payer, individuals are dis-incentivized to purchase private LTC insurance to protect their LTC needs. The introduction of the PLTC program aims to reduce such disincentive by allowing individuals who have purchased LTC insurance to keep an additional amount of assets, which in most cases equals the amount covered by the insurance plan, above the Medicaid threshold and still qualify for Medicaid coverage.

The PLTC program seems to offer a win-win solution. Individuals can protect themselves and not forsake their benefits of using Medicaid. The government would cut its spending on LTC if more individuals purchase LTC insurance. There are other benefits associated with increased insurance take-up. For example, consumers would be granted with more options since some nursing homes might not cover Medicaid patients. Also, having more patients paid by private insurance would encourage nursing home providers to increase quality of care to compete for those patients, because these patients are considered more profitable than Medicaid patients.

The optimism of the PLTC program culminated into a section of the Deficit Reduction Act (DRA) of 2005, which provides permission to all the other states, in addition to the four pilot states (California, Connecticut, Indiana and New York), to enact the PLTC program. By 2010, another 33 states adopted the partnership program. The rollout of the program can be summarized as follows: 2006 (Idaho, Minnesota, and Nebraska); 2007 (Florida, Georgia, Kansas, Maine, Missouri, Montana, North Dakota, New Hampshire, Nevada, Ohio, Pennsylvania, South Dakota, Virginia); 2008 (Arkansas, Arizona, Colorado, New Jersey, Oklahoma, Oregon, Rhode Island, Tennessee, and Texas); 2009 (Alabama, Kentucky, Louisiana, Maryland, South Carolina, Wisconsin, and Wyoming); and 2010 (Iowa). 


\subsection{Earlier Findings}

The existing evidence of the impact of the PLTC program has so far been very limited. The only two studies that we are aware of are McCall et al. (1998) and Lin and Prince (2013). McCall et al. (1998) offer an examination of the types of individuals that have purchased PLTC polices in the original four states. Lin and Prince (2013) take advantage of the rollout of the PLTC program after 2005 to analyze the impact of the program on LTC insurance purchases. They find that the implementation of the PLTC program has, at best, a modest impact on insurance take-up. What's more interesting, they find that when allowing for differential responses across wealth levels, high-asset individuals (above 80th percentile) largely increase their likelihood of purchase (3 percentage points or a 15\% increase of the baseline coverage rate for those individuals), while individuals below the 80th percentile show virtually no response.

\section{Why Only the Rich Respond?}

Previous findings from Lin and Prince (2013) suggest that only the high-asset individuals respond to the program. This result seems surprising. As noted by Brown and Finkelstein (2008), the PLTC program reduces the implicit Medicaid tax by increasing the likelihood of qualifying for Medicaid. However, the implicit tax at high wealth levels is the lowest and the program is expected to have the least effect on reducing such a tax for the rich. Compared to the rich, the middle income group has been considered the target of the PLTC program (e.g., Meiners 2009). This is because middle income group are more likely to go on Medicaid than the rich but have substantial assets they would like to protect, as compared to the poor. It may seem obvious ex ante that this will be the group most likely to respond - the rich and poor see the added benefit of faster Medicaid coverage as minimal, since the former likely won't need it and the latter will tap into Medicaid quickly anyway. Further, to the extent that there is a Medicaid 
stigma, it seems plausible that this may be disproportionately high among the rich, which would further serve to make them less responsive to the PLTC program than the middle class.

However, there are a number of factors that might help explain why high-asset individuals respond more to the program. The first is bequest motive. Several papers (e.g., Sloan and Norton 1997, Lockwood 2011, Brown et al. 2012) have assessed the relationship between LTC insurance purchasing behavior and bequest motives. ${ }^{3}$ In doing so, they cite various reasons why bequest motives may influence LTC insurance purchases, e.g., via a direct increase in demand due to altruism or an impact on the opportunity cost of precautionary saving. Specifically in our case, since the partnership program can increase permanently sheltered assets, individuals' response to this feature may differ depending on their intent to ultimately bequest assets. If high-asset individuals are more likely to have bequest intent, it could help explain the large response of the rich.

The second factor that could drive differential responses to the PLTC program is financial literacy. Previous work has found that financial literacy is associated with better retirement planning (Lusardi and Mitchell, 2007 and 2014) and that cognitive ability plays an important role in purchasing Medigap insurance plans (Fang, Keane and Silverman, 2008). It is reasonable to argue that individuals with a high asset endowment might be more likely to display higher levels of financial literacy. In this case, responding to the PLTC program by the rich might be explained by the level of financial literacy.

The last factor, arguably the most important one, is program awareness. Although the PLTC program has been in place since the 1990s in the four pilot states, it is not until after the passage of the DRA in 2005 that the program started to expand throughout the country. Given that the program is still in its early development stage, the availability and features of the program are not universally known and understood. McCall et al. (1998) find that having talked with a financial planner strongly predicts purchase of LTC insurance. Thus, variation in awareness of the partnership program and its benefits may

\footnotetext{
${ }^{3}$ Previous work has also showed the importance of bequest motives in wealth accumulation and demand for life insurance and annuities, such as Bernheim (1991), Bernheim, Skinner and Weinberg (2001), Dynan, Skinner, Zeldes (2002), Kopczuk and Lupton (2007).
} 
predict response rates to incentives in this market. We hypothesize that the rich are more likely to be exposed to the program. This is possible because they might be more likely to talk to financial planners or they have better access to information through the use of the Internet. ${ }^{4}$

\section{Data and Model}

\subsection{Data and Construction of Key Variables}

Our data come from the Health and Retirement Study (HRS) 2002 to 2010. The HRS is a longitudinal biannual household survey data set for the elderly and near elderly in the U.S. The data offer detailed information about each respondent's demographics, financial wealth, insurance coverage, and health conditions.

Particularly useful to our study, the HRS data contain variables that can measure the three factors that we discuss above. To measure bequest intent, we observe each individual's self-assessed importance of leaving inheritance to their heirs. This information was collected in the 1992 survey, and has been used in, e.g., Sloan and Norton (1997) and Lockwood (2011). ${ }^{5}$ We construct a binary variable equaling one if the respondent indicates that leaving an inheritance is "very important.” To measure awareness levels and financial literacy, we observe whether each individual uses the Internet and whether he/she ever held a job in finance. The former can serve as a proxy for general awareness of the partnership program, as many of the details of the program for each adopting state are available online. The latter serves as a proxy for financial literacy. ${ }^{6}$ It also offers a proxy for an individual's ability to understand the

\footnotetext{
${ }^{4}$ In addition to the national clearinghouse website developed by the secretary of Health and Human Services, all adopting states have used their government websites to provide comprehensive information the partnership program. Our conversation with an Indiana state partnership program director has confirmed to us that the Internet provides the most comprehensive and reliable information about the partnership program.

${ }^{5}$ This variable was only available from the 1992 wave of the survey.

${ }^{6}$ Lusardi and Mitchelli (2011) use respondents' answer to three survey questions to measure financial literature. However, one limitation of using these data is limited sample size (about 1,600 unique individuals). We find the results are hard to interpret due to loss of precision. See Lusardi and Mitchelli (2014) for an excellent review of recent development in research on financial literacy.
} 
benefits the PLTC program due to financial training. We then construct binary variables equaling one if the individual used the web by 2008 or ever held a finance-related job, respectively. ${ }^{7}$

The HRS data is merged with state policy adoption data using each individual's information concerning state of residence. Most of the policy data were collected from a database of Thomson Reuters through http://w2.dehpg.net/LTCPartnership/. More details regarding the source of the data on implementation and the program could be found in Lin and Prince (2013).

Table 1 provides summary statistics of the variables used in the analysis. ${ }^{8}$ The final sample consists of a total of 39,151 observations for 12,695 unique individuals. All the statistics are calculated using individual sampling weights. Over the entire sample, the average insurance take-up is about $11 \%$. On average, about 37\% of the observations have been exposed to the PLTC program in the data. Regarding our measure of bequest intents, awareness level and financial literacy, about $22 \%$ of the observations think leaving inheritance is very important; about $61 \%$ use Internet to gather information and check emails; and about $10 \%$ had any job experience related to finance.

\subsection{Model}

To allow for differential responses to the program according to the realization of these dichotomous variables as well as asset levels, we estimate the following linear probability model controlling for state fixed effects, year fixed effects, state-level linear time trends, individual fixed effects, and time-varying individual characteristics:

\footnotetext{
${ }^{7}$ HRS provides data on web usage since 2002. Our analysis uses the 2008 data. Although not reported in the paper, we have also used alternative years' data (e.g., year 2002 and year 2006) to measure web usage and the results are consistent,

${ }^{8}$ Observations at the person-year level are weighted using individual-level weights.
} 
(1)

$$
\mathrm{y}_{\text {it }}=\alpha+\gamma_{1} \mathrm{LA}_{\text {it }} \mathrm{P}_{\mathrm{st}}+\gamma_{2} \mathrm{MA}_{\text {it }} \mathrm{P}_{\mathrm{st}}+\gamma_{3} \mathrm{HA}_{\mathrm{it}} \mathrm{P}_{\mathrm{st}}+\gamma_{4} \mathrm{LA}_{\mathrm{it}} \mathrm{P}_{\mathrm{st}} \mathrm{I}\left(\mathrm{X}_{\mathrm{it}}=1\right)+\gamma_{5} \mathrm{MA}_{\text {it }} \mathrm{P}_{\mathrm{st}} \mathrm{I}\left(\mathrm{X}_{\mathrm{it}}=1\right)+
$$

$\gamma_{6} \mathrm{HA}_{\mathrm{it}} \mathrm{P}_{\mathrm{st}} \mathrm{I}\left(\mathrm{X}_{\mathrm{it}}=1\right)+\mathrm{Z}_{\mathrm{it}} \beta+\mathrm{LA} \mathrm{A}_{\mathrm{it}} \mathrm{I}\left(\mathrm{X}_{\mathrm{it}}=1\right)+\mathrm{MA}_{\mathrm{it}} \mathrm{I}\left(\mathrm{X}_{\mathrm{it}}=1\right)+\mathrm{HA}_{\mathrm{it}} \mathrm{I}\left(\mathrm{X}_{\mathrm{it}}=1\right)+\eta_{\mathrm{t}}+\sigma_{\mathrm{s}}+\eta_{\mathrm{s}} \mathrm{t}+$

$\mu_{\mathrm{i}}+\varepsilon_{\mathrm{ist}}$

The dependent variable, $y_{i t}$, is a dichotomous variable indicating whether an individual $i$ has private longterm care insurance coverage at year $t$. The policy variable $P_{s t}$ is a dichotomous variable indicating whether the partnership program is being implemented in a state $s$ at year $t$.

The three asset dummies $\left(L A_{i t}, M A_{i t}\right.$, and $\left.H A_{i t}\right)$ indicate low assets (below the 50th percentile in the data), medium assets, (50th to 80th percentile), or high assets (above the 80th percentile), respectively. $Z_{i t}$ consists of time-varying individual characteristics: age, marital status, self-reported health, body mass index (BMI), assets (logarithm), income (logarithm), and number of children.

We use variable $\mathrm{X}$ to denote each of the three dichotomous variables defined above to capture bequest motives, financial literacy and program awareness. The model estimates whether, given an asset level, response to the program depends on $\mathrm{X}$, and whether differential responses to the program along the asset dimension depend on $\mathrm{X}$ (captured by $\left.\gamma_{4}-\gamma_{6}\right)$. Note that we also control for $\mathrm{LA}_{\mathrm{it}} \mathrm{I}\left(\mathrm{X}_{\mathrm{it}}=\right.$ 1), $\mathrm{MA}_{\mathrm{it}} \mathrm{I}\left(\mathrm{X}_{\mathrm{it}}=1\right)$, and $\mathrm{HA}_{\mathrm{it}} \mathrm{I}\left(\mathrm{X}_{\mathrm{it}}=1\right)$ in the above specification. The remaining components of the model include time fixed effects $\left(\eta_{t}\right)$, state fixed effects $\left(\sigma_{s}\right)$, state-level time trends $\left(\eta_{s} t\right)$, and individual fixed effects $\left(\mu_{\mathrm{i}}\right){ }^{9}$ The final term, $\varepsilon_{\text {ist }}$, captures unobservables at the individual-state-year level that impact the decision to purchase long-term care insurance.

\section{Findings}

Table 2 summarizes our main results, where we consider three plausible drivers of individuals' response to the partnership program: bequest intent, financial literacy, and awareness levels. The first column

\footnotetext{
${ }^{9}$ With the inclusion of individual fixed effects, state fixed effects are identified through individuals moving across states over time.
} 
replicates the results in Lin and Prince (2013) that the effect of the PLTC program was entirely driven by the rich. The second column suggests that bequest motives may be predictive of response to the program. Specifically, wealthy individuals with relatively high bequest motives respond to the program less than wealthy individuals with relatively low bequest motives (as captured by the point estimate of -0.044). This result is consistent with the idea that wealthy individuals with bequest motives are less responsive to insurance incentives. This may be the case if they are more likely to self insure (Lockwood, 2011). However, while this is a suggestive finding, the coefficient is not statistically significant (but does have pvalue below 0.12). Further, these results are for a select group that answered the bequest question in 1992; in particular, this subsample is notably older. ${ }^{10}$ Consequently, as might be expected, this group in general responds less to the PLTC program ${ }^{11}$, since they are relatively closer to an age when purchasing LTC insurance in general is less attractive. For these reasons, we take this difference in response due to bequest motive as suggestive only.

The last two columns of Table 2 indicate financial literacy and awareness levels are predictive of response to the program. Regarding financial literacy, we find that middle-asset individuals who are financially literate do notably respond to the program, while those who aren't (according to our proxy) do not. High-asset individuals respond strongly to the program whether financially literate or not; however, the response is notably stronger among those who are. This last finding is not statistically significant, although the point estimate is quite large (three percentage points on a base of about 18 percent). Regarding awareness levels, use of the Internet for information is clearly a necessary condition for response to the program. Even the wealthy show no response if they do not use the Internet. Hence, the Internet appears to proxy for a very baseline awareness level, i.e., awareness that the program exists at all. Taken together, these results suggest that awareness, as proxied by web usage, is a requirement for

\footnotetext{
${ }^{10}$ The mean age for this sample is 64.6, but is 60.1 for the whole sample.

${ }^{11}$ We even find a negative response for those with low assets. This may be due to PLTC plans being required to have minimum coverage levels. If the program crowds out any low-coverage plans, it would raise the average plan price (ceteris paribus) and possibly dissuade low-asset individuals from making a purchase
} 
individuals to respond to the program, and response is bolstered when one has a stronger understanding of the benefits, as proxied by experience in the financial sector.

Our finding about awareness and understanding of the program adds to the existing literature on understanding saving and insurance purchase behavior for the elderly population. When we look at differential responses to the program along wealth levels, we see that the differences we found in column 1 persist, even after controlling for bequest motives and awareness. ${ }^{12}$ They do disappear for those who don't get information via the Internet, but this is only because no one in this group responds to the program. Further, there does appear to be a response to the program for middle-asset individuals with financial experience, so while the response is still increasing in wealth for this subgroup, it is not a stark jump at the high wealth level.

In sum, the results in Table 2 show that differences in financial literacy, and awareness, can help explain differential responses to PLTC, in addition to wealth levels. Further, the strong persistence of a wealth effect despite these added controls indicates that Medicaid implicit tax is likely the key driver of differential responses to the program across wealth levels.

We conclude this section by noting that, while these additional variables (importance of bequest, Internet usage, and finance job experience) may proxy for bequest intent, program awareness, and understanding of program benefits, they may also capture other variables that affect LTC insurance purchasing behavior. This could have consequences when trying to make causal interpretations. To this concern, we note the following. First, our additional variables vary at the individual level (not individualyear level), so any other variables correlated with “importance of bequest,” "Internet usage,” or "financial experience” that affect LTC insurance purchases are captured by our individual-level fixed effects. Consequently, our causal interpretation is flawed only if our three additional variables are correlated with other variables that generate a differential response to the partnership program. One such variable might be wealth; however, we allow for a differential response along wealth levels, and our results indicate that

\footnotetext{
${ }^{12}$ The effect is smaller for our analysis of bequest motive. However, as noted above, the subsample used for this analysis is significantly older than our full sample, making the baseline response to the program smaller.
} 
wealth differences cannot explain the differential responses we find along these three additional variables. Although we cannot identify an obvious variable that both would generate a differential response to the partnership program for reasons other than bequest motive and/or awareness and would be correlated with one of our additional measures, we concede that one may exist. Hence, our causal interpretations above should be taken with that caution in mind.

\section{Conclusion}

Building on the findings of Lin and Prince (2013) concerning the relationship between response to the partnership program and wealth, in this paper we analyzed several additional possible determinants of response. The determinants we considered were bequest motives, financial literacy, and program awareness. Controlling for these variables may dampen the wealth effects found in Lin and Prince (2013), or prove to be additional determinants of individuals' program response, beyond wealth. We found mild evidence that intent to bequest influences individual purchases of the partnership program. However, we found strong evidence that awareness, as proxied by Internet usage, is crucial for response. Further, financial literacy notably increases responsiveness. In particular, financial literacy is sufficient for individuals with middle-level assets to respond to the program, although still not as much as those with high assets. Finally, even with controls for these additional individual characteristics, a difference in response across wealth levels persists, suggesting that Medicaid crowd-out is still important in determining uptake of this program.

These findings have two clear policy implications, if the government wishes to increase participation in the partnership program, particularly among middle-asset individuals. First, given the importance of financial literacy, the government needs to educate consumers about the program's benefits to achieve the success of any policy intervention. Second and even more importantly, the government needs to increase efforts to create awareness of the program among the middle class. 


\section{References}

Bernheim, B. D. 1991. How strong are bequest motives? Evidence based on estimates of the demand for life insurance and annuities. Journal of Political Economy 99(5): 899-927.

Bernheim, B. D., Skinner, J. and Weinberg S.2001. What accounts for the variation in retirement saving across U.S. households? American Economic Review 91(4): 832-57.

Brown, J. and Finkelstein, A. 2008. The interaction of public and private insurance: Medicaid and the long-term care insurance market. American Economic Review 98(3): 1083-1102.

Brown, J., Goda, G., and McGarry, K. 2012. Long-term care insurance demand limited by beliefs about needs, concerns about insurers, and care available from family. Health Affairs 31 (6): 1294 -1302.

Dynan, K., Skinner, J., and Zeldes, S. 2002. The importance of bequests and life cycle saving in capital accumulation: A new answer. American Economic Review Papers and Proceedings 92(2): 274-78.

Fang, H., Keane, M., and Silverman, D. 2008. Sources of advantageous selection: Evidence from the Medigap insurance market. Journal of Political Economy, 116: 303--350.

Kopczuk, W. and Lupton J. 2007. To leave or not to leave: The distribution of bequest motives. The Review of Economic Studies 74(1): 207-235.

Lin, H. and Prince, J. 2013. The impact of the partnership long-term care insurance program on private coverage. Journal of Health Economics 32: 1205-1213.

Lusardi, A. and Mitchell, O. S. 2007. Baby boomer retirement security: The roles of planning, financial literacy, and housing wealth. Journal of Monetary Economics 54(1): 205-224.

Lusardi, A. and Mitchell, O.S. 2011. Financial literacy and planning: Implications for retirement wellbeing. In Financial Literacy: Implications for Retirement Security and the Financial Marketplace, edited by Olivia S. Mitchell and Annamaria Lusardi, 17-39. Oxford and New York: Oxford University Press.

Lusardi, A. and Mitchell, O.S. 2014. The economic importance of financial literacy: Theory and evidence. Journal of Economic Literature 52(1): 5-44.

Lockwood, L. 2011. Incidental bequests: bequest motives and the choice to self-insure late-life risks. NBER working paper.

McCall, N., Mangle, S., Bauer, E., and Knickman, J. 1998. Factors important in the purchase of partnership long-term care insurance. Health Services Research 32(2): 187-203.

Meiners, M. 2009. Long-term care insurance partnership: considerations for cost-effectiveness. Center for Health Care Strategies, Inc. Issue brief.

Sloan, F. and Norton, E. 1997. Adverse selection, bequests, crowding out, and private demand for insurance: evidence from the long-term care insurance market. Journal of Risk and Uncertainty 12(1): 6576. 
$\underline{\text { Table } 1}$

Summary Statistics

\begin{tabular}{|c|c|c|c|c|c|}
\hline Variable & $\underline{\text { Mean }}$ & $\underline{\text { Std. Dev. }}$ & $\underline{\text { Min }}$ & $\underline{\text { Max }}$ & $\underline{\mathbf{N}}$ \\
\hline Long-term Care Insurance & 0.115 & 0.319 & 0 & 1 & 39151 \\
\hline States Adopted PLTC & 0.367 & 0.482 & 0 & 1 & 39151 \\
\hline Age & 60.138 & 4.838 & 50 & 69 & 39151 \\
\hline Married & 0.689 & 0.463 & 0 & 1 & 39151 \\
\hline Self-reported Health & 2.649 & 1.100 & 1 & 5 & 39151 \\
\hline BMI & 28.549 & 5.903 & 7 & 82.700 & 39151 \\
\hline Number of Children & 2.882 & 1.899 & 0 & 19 & 39151 \\
\hline (Log) Assets & 11.528 & 2.502 & 0 & 18.178 & 39151 \\
\hline (Log) Income & 10.503 & 1.496 & 0 & 16.798 & 39151 \\
\hline $\begin{array}{c}\text { Leaving Inheritance is very } \\
\text { important }\end{array}$ & 0.224 & 0.417 & 0 & & \\
\hline Uses web as of 2008 & 0.613 & 0.487 & 0 & 1 & 18679 \\
\hline Worked in finance & 0.093 & 0.291 & 0 & 1 & 35805 \\
\hline
\end{tabular}

Note: All figures use individual weights, and change minimally without weighting. The sample includes a total of 39,151 observations for 12,695 unique individuals. The final sample varies for each regression due to missing data on the three key explanatory variables: bequest, Internet use, and finance-related jobs. Self-reported Health ranges from 1 to 5, with 1 being excellent and 5 being poor. 
$\underline{\text { Table } 2}$

Estimates for the effect of the PLTC Program, allowing for differential effects according to bequest incentives, knowledge of finance, and internet usage

\begin{tabular}{|c|c|c|c|c|}
\hline Variable & & $\frac{X=I \text { (Bequest }}{\underline{\text { Very High) }}}$ & $\frac{X=I(\text { Worked in }}{\text { Finance })}$ & $\underline{\mathrm{X}=\mathrm{I} \text { (Uses Web }}$ \\
\hline PLTC*LowAssets & $\begin{array}{c}-0.015 \\
(0.009)\end{array}$ & $\begin{array}{l}-0.027 * \\
(0.012)\end{array}$ & $\begin{array}{l}-0.010 \\
(0.011)\end{array}$ & $\begin{array}{c}-0.014 \\
(0.010)\end{array}$ \\
\hline PLTC*MidAssets & $\begin{array}{r}-0.005 \\
(0.009)\end{array}$ & $\begin{array}{l}-0.007 \\
(0.009) \\
\end{array}$ & $\begin{array}{c}-0.004 \\
(0.012)\end{array}$ & $\begin{array}{l}-0.016 \\
(0.012) \\
\end{array}$ \\
\hline PLTC*HighAssets & $\begin{array}{c}0.025 * * \\
(0.008)\end{array}$ & $\begin{array}{c}0.016 \\
(0.016) \\
\end{array}$ & $\begin{array}{c}0.035 * * \\
(0.013) \\
\end{array}$ & $\begin{array}{c}-0.021 \\
(0.017) \\
\end{array}$ \\
\hline PLTC*LowAssets* $(\mathrm{X}=1)$ & & $\begin{array}{c}0.010 \\
(0.021) \\
\end{array}$ & $\begin{array}{l}-0.027 \\
(0.020) \\
\end{array}$ & $\begin{array}{c}0.008 \\
(0.009) \\
\end{array}$ \\
\hline PLTC*MidAssets* $(\mathrm{X}=1)$ & & $\begin{array}{c}0.004 \\
(0.019)\end{array}$ & $\begin{array}{l}0.042+ \\
(0.024)\end{array}$ & $\begin{array}{l}0.023+ \\
(0.012)\end{array}$ \\
\hline PLTC*HighAssets* $(X=1)$ & & $\begin{array}{l}-0.044 \\
(0.028)\end{array}$ & $\begin{array}{c}0.031 \\
(0.037) \\
\end{array}$ & $\begin{array}{l}0.063 * * \\
(0.015)\end{array}$ \\
\hline MidAssets & $\begin{array}{c}0.005 \\
(0.006)\end{array}$ & $\begin{array}{l}-0.003 \\
(0.008)\end{array}$ & $\begin{array}{c}0.003 \\
(0.008)\end{array}$ & $\begin{array}{c}0.006 \\
(0.011)\end{array}$ \\
\hline HighAssets & $\begin{array}{c}0.001 \\
(0.007) \\
\end{array}$ & $\begin{array}{l}-0.003 \\
(0.013)\end{array}$ & $\begin{array}{l}-0.005 \\
(0.008) \\
\end{array}$ & $\begin{array}{c}0.010 \\
(0.012) \\
\end{array}$ \\
\hline Observations & 39151 & 18679 & 31914 & 35805 \\
\hline R-squared & 0.015 & 0.027 & 0.020 & 0.018 \\
\hline
\end{tabular}

Note: All regressions include a constant term, individual fixed effects, year fixed effects, and state liner time trends, and controls for: income, age, marital status, self-reported health, BMI, and number of children. All regressions also include asset level dummies interact with the dummy for $\mathrm{X}=1$. Robust standard errors, clustered at the state level, in parentheses. Individual weighting is used to represent the whole population. Results with no weighting are very similar. ** is significant at the $1 \%$ level; * is significant at the $5 \%$ level; + is significant at the $10 \%$ level. R-squared is for within variation. 